\title{
Patronazgo artístico en la Edad Moderna: los marqueses de los Vélez y la iglesia de San Antonio de Padua en Mazarrón (Murcia)
}

\author{
Artistic patronage in the Modern Age: the Vélez marquisate and \\ the Church of San Antonio de Padua in Mazarrón (Murcia)
}

\author{
ÁLVARO CÁNOVAS MORENO \\ Universidad Autónoma de Madrid \\ alvarocanovasmoreno@gmail.com
}

\begin{abstract}
Resumen: La iglesia de San Antonio de Padua de Mazarrón (Murcia), cuya fundación podemos fechar entre finales del siglo XV y mediados del XVI, fue erigida por la influencia y el poder que el marquesado de los Vélez ejerció en el lugar mediante la explotación del mineral del alumbre. Posteriormente, el templo sufrió diferentes reformas y ampliaciones, modificando su sencilla estructura original hasta conferirle las características que definen el edificio en la actualidad. Este trabajo analiza el desarrollo constructivo de la iglesia, así como la intervención y el patronazgo de los marqueses en ella, especialmente desde finales del siglo XVII hasta principios del XVIII. Una intervención que, como hemos demostrado, resultó - por lo general — un hecho más aparente que real, puesto que el marquesado no sufragó la totalidad de las obras.
\end{abstract}

Además de otros aspectos, en este trabajo se han investigado tanto la cronología como el desarrollo histórico-artístico de un templo que no había sido profundamente estudiado, y del que no se ha conservado libro de fábrica alguno. También se han aportado nuevos datos mediante el análisis de documentación inédita.

Palabras clave: Iglesia San Antonio de Padua, Mazarrón, marquesado de los Vélez, patronazgo artístico, Fernando de Aragón y Moncada.

\begin{abstract}
The church of Saint Anthony of Padua (Mazarrón, Murcia), dated from the end of the 15th century to the middle of the 16th century, was built due to the influence and power that the Velez marquisate had on Mazarrón by the exploitation of alum ore. The temple underwent several reforms and extensions over time, modifying its simple original structure to give it the characteristics that define the building today. In this paper we aim to study the patronage of such marquisate on the temple, especially from the end of the 17 th century to the beginning of the 18th century. We have proved that this patronage was not completely true, and the building work was not totally sponsored.
\end{abstract}

In addition to other aspects, this paper also studies the chronology and the artistic and Recibido: 18 de julio de 2018; aceptado: 25 de octubre de 2018; publicado: 30 de marzo de 2019.

Revista Historia Autónoma, 14 (2019), pp. 37-54

DOI: https://doi.org/10.15366/rha2019.14.002 
historic development of the church, which has not been properly studied and whose books of factory have not been preserved. We have also added unpublished information verified with already known sources.

Keywords: San Antonio de Padua church, Mazarrón, Vélez marquisate, artistic patronage, Fernando de Aragón y Moncada.

\section{Introducción}

Figura 1: Iglesia de San Antonio, Mazarrón, Murcia. Fachada principal y detalle de la misma: Escudo nobiliario de Fernando de Aragón y Moncada (príncipe duque de Montalto, VII marqués de los Vélez).
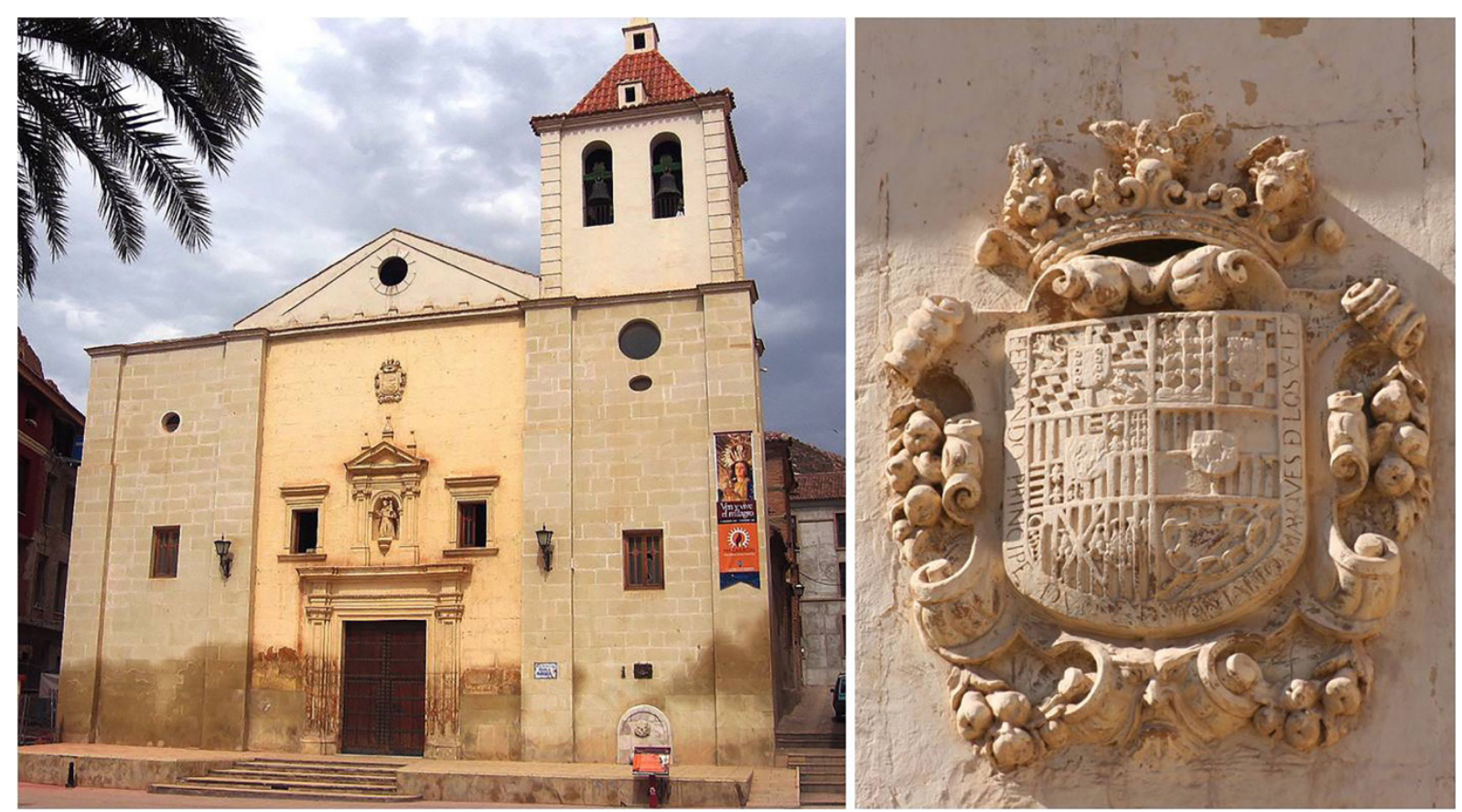

Fuente: Imagen del autor.

La presente investigación ${ }^{1}$ ha tratado de aclarar el origen y desarrollo constructivo de la iglesia parroquial de San Antonio de Padua de Mazarrón (Murcia) [fig. 1]. Paralelamente, se ha pretendido esclarecer la influencia ejercida por este marquesado en el patronazgo del templo, aportando para ello documentación inédita, así como nuevas interpretaciones al respecto.

La iglesia de San Antonio, actualmente cerrada al culto, se halla en un luctuoso estado de conservación; precisando una profunda restauración. Por este motivo, y ante la falta de

\footnotetext{
${ }^{1}$ Este trabajo fue financiado por la Beca de Colaboración concedida para el Departamento de Historia del Arte de la Universidad de Murcia. Debemos agradecer la desinteresada colaboración del profesor Pedro Segado, así como la cesión de los planos del templo por parte de J. de Dios de la Hoz.
} 
investigaciones que analicen el templo en profundidad, resulta pertinente llevar a cabo trabajos que aborden estos asuntos.

1. Mazarrón y el alumbre: «ambición, intrigas, riqueza y poder»²

La fundación de esta iglesia de San Antonio estuvo estrechamente ligada a las explotaciones mineras del alumbre en Mazarrón. Ya que, a partir de 1462, tras el descubrimiento de las minas de alumbre en la comarca, Enrique IV concedió los derechos de explotación a su favorito, Juan Pacheco (1419-1474), I marqués de Villena, quien cedió a su vez la mitad de estos derechos al adelantado mayor del Reino de Murcia, Juan Chacón (1452-1503), padre del futuro I marqués de los Vélez. Con el establecimiento de estas industrias, y el consiguiente crecimiento urbano y demográfico de Mazarrón, pronto surgió la necesidad de levantar templos adecuados a un nuevo contexto social y económico.

La población, conocida como «Casas de los Alumbres de Almazarrón», era dependiente del concejo de Lorca, con carácter de realengo; y se encontraba dividida en dos barrios de influencia, donde cada uno de estos marqueses había fundado un templo religioso y una fortaleza. Así, el marquesado de Villena fundó una ermita dedicada a San Andrés, de igual modo que el de los Vélez erigió un primitivo templo consagrado a San Antonio de Padua ${ }^{3}$.

Durante los primeros años, el laboreo del alumbre en la zona fue desarrollándose progresivamente. Diego López Pacheco, III marqués de Villena, se alió con el I marqués de los Vélez, Pedro Fajardo Chacón, para alcanzar un acuerdo con el papa Clemente viI, propietario de las minas de Tolfa. Tras el pacto, el alumbre mazarronero alcanzó sus mayores cotas de producción ${ }^{4}$; lo que provocó que, en 1572, la población se segregara del concejo de Lorca, otorgándole Felipe II término propio y rango de villa. Sin embargo, a finales del siglo XVI, comenzó el declive general del alumbre hispánico, que finalizó en 1595 con el cierre de las explotaciones en Mazarrón ${ }^{5}$.

A lo largo del siglo XVII, los intentos de reapertura del negocio resultaron inútiles. Por ello, la población buscó alternativas de subsistencia impulsando el negocio de un derivado del alumbre: la almagra; además de la explotación de la pesca, el esparto, las salinas, o la recogida

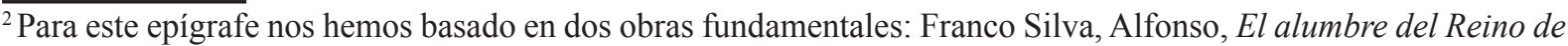
Murcia, una historia de ambición, intrigas, riqueza y poder, Murcia, Academia Alfonso X, 1996 y Ruiz Martín, Felipe, Los alumbres españoles. Un índice de coyuntura económica europea en el siglo XVI, Madrid, Bornova y Fundación de Historia moderna, 2005.

${ }^{3}$ Gutiérrez-Cortines, Cristina, Renacimiento y arquitectura religiosa en la antigua diócesis de Cartagena, Murcia, Colegio de aparejadores y arquitectos técnicos, 1987, pp. 461-464.

${ }^{4}$ Ruiz Martín, Felipe, Los alumbres... op. cit., p. 71.

${ }^{5}$ Franco Silva, Alfonso, El alumbre... op. cit., p. 109.
} 
de barrilla ${ }^{6}$. Ante esta coyuntura, el marquesado de los Vélez comenzó a desinteresarse por el lugar.

A comienzos del siglo XVIII, la población seguía fundamentando su economía en la producción de almagra ${ }^{7}$. No obstante, a lo largo de esta centuria tuvo lugar un paulatino crecimiento económico y demográfico.

\section{El marquesado de los Vélez: patronazgo artístico —y de la memoria-.}

En este epígrafe hemos tratado de analizar el fenómeno del patronazgo artístico en la Edad Moderna, centrándonos en la casa de los Vélez y su relación con la iglesia de San Antonio. Sobre todo, además del hecho de favorecer y amparar una fundación, hemos querido subrayar aquí el patronazgo como fenómeno esencial para la creación de la memoria de una familia o institución: ese «patronazgo de memorias» citado ya por Covarrubias. Destacando, asimismo, el importante papel que jugaron las «imágenes» en el proceso, ya que la nobleza de la Edad Moderna no solo proyectó su poder simbólico en sus dominios mediante el impulso de obras arquitectónicas, sino que estas solo eran un eslabón más dentro de una compleja cadena representativa que comprendía otros elementos tales como pinturas, objetos litúrgicos o, como en el caso de nuestro templo, la heráldica ${ }^{8}$. Solo a través de estas hipótesis entenderemos la continua ambición de aquellos nobles por el patronazgo.

El marquesado de los Vélez sobresale como uno de los ejemplos más excelsos de patronazgo artístico moderno del Levante español. Siendo esta casa especialmente importante para el devenir histórico - y artístico — del antiguo Reino de Murcia, y para el territorio que hoy corresponde a la actual provincia de Almería; unas zonas que conformaban la mayor parte de sus dominios, y donde desarrollaron diferentes actividades económicas, obteniendo de ellas ingentes beneficios. Solo así consiguieron situarse, durante más de tres siglos, como una de las dinastías más influyentes del sureste español. Preeminencia en la que el alumbre jugó un papel decisivo como fuelle económico de sus haciendas, sirviendo muchas veces de financiación para

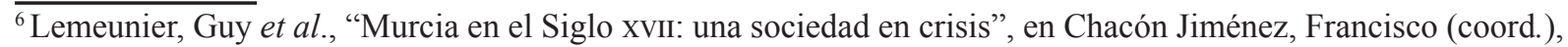
Historia de la Región murciana, Murcia, Mediterráneo, Tomo VI, pp. 2-233.

${ }^{7} \mathrm{La}$ documentación que hemos hallado prueba la relevancia de este material, incluso en la Corte: Archivo General de Palacio, Sección de la Real Fábrica de Cristales, Solicitud de 50 arrobas de almagre de Mazarrón para el pulimento de cristales planos, 1778, Caja 781, Exp. 22.

${ }^{8}$ Para estas líneas nos hemos basado en: Pereda, Felipe, "Mencía de Mendoza, Mujer del I Condestable de Castilla: el significado del patronazgo femenino en la Castilla del siglo XV", en Alonso, Begoña et al. (coord.), Patronos y coleccionistas, los Condestables de Castilla y el Arte (Siglos XV-XVII), Valladolid, Universidad de Valladolid, 2005, pp. 12-16.
} 
las grandes empresas artísticas emprendidas por el marquesado. De hecho, el usufructo de los alumbres de Mazarrón se convirtió en su mayor fuente de ingresos durante todo el siglo XVI ${ }^{9}$.

Generalmente, el poder de estas familias era medido a través de la relevancia de los encargos artísticos que generaban. Así, evidenciando una innegable hegemonía económica y política, el I marqués de los Vélez, Pedro Fajardo y Chacón (1478 Ca.-1546), llevó a cabo una de las empresas artísticas más interesantes del primer Renacimiento español: el patio del palacio fortificado de Vélez-Blanco. Mediante esta obra, y de una manera muy simbólica, el marqués hizo manifiesta su refinada sensibilidad artística que, por el contrario, no se desarrolló de la misma forma en otras familias nobiliarias de aquel momento.

Siguiendo esa línea de ambición propagandística destacaremos, como «gloria de un linaje» ${ }^{10}$, la construcción de la monumental Capilla de los Vélez (1490-1507) en la catedral de Murcia.

Las órdenes religiosas también fueron protagonistas de la protección de estos linajes nobiliarios. En el caso de los Vélez, el continuo patrocinio a la Orden franciscana resulta incuestionable. Dentro de esta dilatada tradición sobresale la figura de Fernando Joaquín Fajardo (1635-1693), vi marqués de los Vélez y hermano de la viI marquesa de los Vélez, María Teresa Fajardo (1645-1715), la cual intervino en la ampliación de la iglesia de San Antonio. Este vi marqués fue un importante benefactor de la Orden franciscana, erigiendo conventos en Martorell y en sus dominios murciano-granadinos ${ }^{11}$ : una labor que se ha entendido incluso como una «refundación de la memoria familiar a finales del siglo XVII» ${ }^{12}$.

En el caso de la iglesia de Mazarrón, el aparato propagandístico se focaliza en su fachada, coronada por el escudo del que fue viI duque de Montalto, príncipe de Paternó y viI marqués de los Vélez, Fernando de Aragón y Moncada (1644-1713) [fig. 1]. Un personaje que manifestó gran predisposición para el mecenazgo y patrocinio de las artes; lo que resulta evidenciable a través de su importante colección de tapices — una de las mejores del siglo XVII ${ }^{13}$ —, o la donación de un estuche-relicario para la Cruz de Caravaca en 1711.

A pesar del acrecentado gusto por el patronazgo artístico de este marqués, y de la larga tradición que vinculaba el linaje velezano con el patronato de San Antonio, no parecía quedar

\footnotetext{
${ }^{9}$ Rodríguez Pérez, Raimundo, "La Casa de los Vélez. Mecenazgo y poder simbólico en la Edad Moderna", en Norba, 24 (2011), pp. 97-110. «http://www.historiauex.es/data/catalogues/493/docs/1443783822.pdf» [consultado el 12 de mayo de 2016].

${ }^{10}$ Belda Navarro, Cristóbal y Elías Hernández Albaladejo, El Arte en la Región de Murcia: de la Reconquista a la Ilustración, Murcia, Tres fronteras, 2006, p. 96. Más concretamente, véase: Rodríguez G. de Ceballos, Alfonso, "La capilla funeraria de los Vélez en la catedral de Murcia", en Anuario del Departamento de Historia y Teoría del Arte, 16 (2004). «https://repositorio.uam.es/handle/10486/1020» [consultado el 07 de mayo de 2016].

${ }^{11}$ Ibidem, p. 109.

${ }^{12}$ Hernández Franco, Juan y Raimundo Rodríguez Pérez, "La Casa aristocrática de los Vélez y la solicitud de la grandeza de España de primera clase”, en Andujar Castillo, Francisco y Julián Pablo Díaz López (coords.), Los señoríos en la Andalucía moderna. El marquesado de los Vélez, Almería, Instituto de estudios almerienses, 2007, pp. 307-319.

${ }_{13}^{13}$ García Calvo, Margarita, “Correspondencia entre Fernando de Aragón (1644-1713), 8º Duque de Montalto, y su agente en Bruselas sobre la realización de la tapicería de la Historia de la Casa de los Moncada”, en Archivo español de Arte, 84, 335 (2011), p. 1. DOI: https://doi.org/10.3989/aearte.2011.v84.i335
} 
del todo claro el motivo que llevó a Fernando de Aragón a favorecer, al menos en parte, la ampliación de este templo; una obra que hemos fechado entre finales del siglo XVII y principios del XVIII, tiempo en el que Mazarrón le resultaba de escaso interés al marquesado ${ }^{14}$. Sin embargo, este trabajo defiende que, con toda seguridad, esta intervención vino impulsada a través de la relación que existió entre Fernando de Aragón y Diego Alemán Peregrín «gobernador general y juez de apelaciones del Estado del excelentísimo señor duque de Montalto y marqués de los Vélez»; quien, en 1698, tomó como esposa a la hermana del presbítero de San Antonio de Padua, María Josefa Jorquera, cuya dote matrimonial hemos descubierto ${ }^{15}$. Además, la obra fue aprovechada por el marqués para llevar a cabo una maniobra de propaganda personal, ya que en el escudo de la fachada antepuso su título de «príncipe duque de Montalto» a los títulos obtenidos a través del casamiento con la heredera de los Vélez, María Teresa Fajardo.

\section{La iglesia de San Antonio de Padua: un estudio histórico-artístico}

\subsection{La iglesia de San Antonio: arte y arquitectura}

Figura 2: Iglesia de San Antonio, Mazarrón, Murcia. Sección longitudinal por nave central según Juan de Dios de la Hoz. En gris claro se aprecian las decoraciones añadidas (pilastras, capiteles, etcétera.) en la malograda reforma de los años 80 .

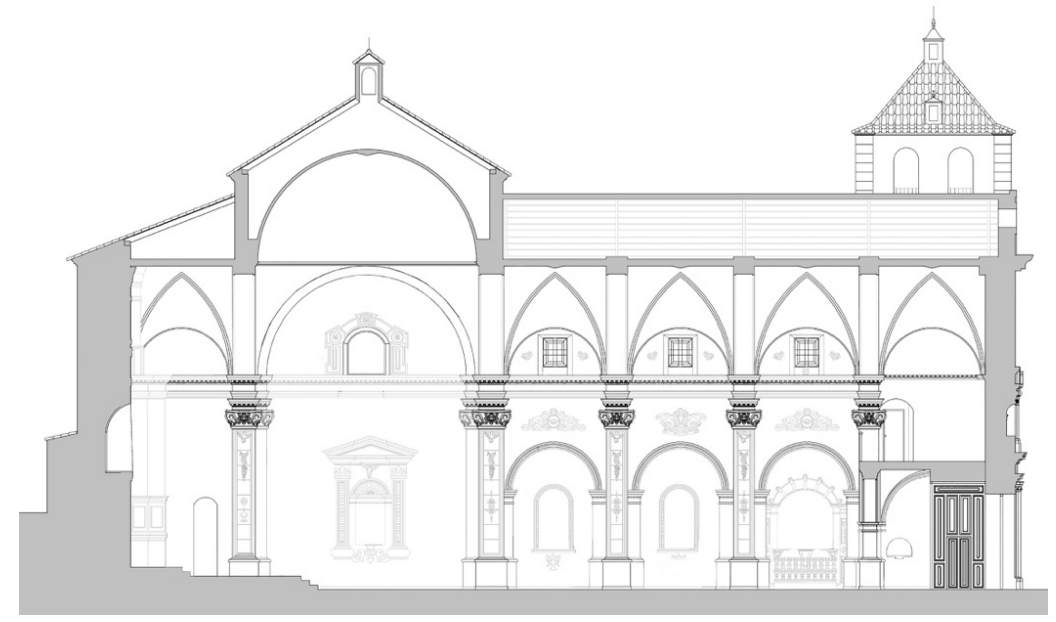

Fuente: J. D. de la Hoz (tomada de su proyecto de restauración).

A través de este estudio histórico-artístico alcanzaremos una mayor compresión totalitaria, así como una datación más aproximada del edificio; ya que hasta la fecha, las trazas, modelos e influencias presentes en la obra no habían sido tratadas en profundidad.

\footnotetext{
${ }^{14}$ Desinterés que queda reflejado en el diario de viaje del x marqués de los Vélez. Véase: Lentisco Puche, José y Julián Díaz López, El señor en sus estados, diario de un viaje de D. Antonio Álvarez de Toledo, X marqués de los Vélez, a sus posesiones de los reinos de Murcia y Granada 1769-1770, Almería, Centro de Estudios Velezanos, Ay. de Vélez-Rubio, 2006.

${ }^{15}$ Archivo General de la Región de Murcia [en adelante, AGRM], Notariado, ante Fernando Vivanco, Mazarrón de 1718-21, dote matrimonial de $\mathrm{M}^{\mathrm{a}} \mathrm{J}$. Jorquera y Diego Alemán, 1698, prot. 6814, f. 64-73V.
} 
Obviando las malogradas modificaciones de los últimos años, podemos definir esta iglesia de San Antonio como un templo de grandes dimensiones, cuyo interior se caracteriza por una serena proporción y una desnudez decorativa; aspectos que incrementan su proporcionada elegancia y esbeltez. La pureza de la línea prevalece ante una decoración casi inexistente, a excepción de algunos detalles como florones y molduras, coincidiendo con el estilo decorativo geométrico del Hermano Bautista, y con la moda imperante de aquel siglo XVII español [fig. 5 y 6$]^{16}$.

En general, el templo puede ser encuadrado dentro del denominado «estilo herreriano»o «escurialense», descendiente de la estética contrarreformista, que aparece tras la construcción del monasterio de El Escorial y el Concilio de Trento; unas características que ya no resultan tan evidentes debido a las desafortunadas restauraciones que ha sufrido el templo, como bien podemos apreciar en las fotografías aportadas.

El sobrio estilo con el que fue erigida inicialmente, la hace única en toda la Región de Murcia, ya que carecemos de muchos ejemplos de esta tipología arquitectónica, a excepción de la iglesia de San Diego de Lorca y los templos de San Joaquín y de la Asunción de Cieza.

La iglesia se estructura a través de una planta longitudinal [fig. 3] conformada por tres naves. La central, que es el doble de las laterales, se articula mediante arcos fajones de medio punto rebajados, cuyos tramos se corresponden con las capillas laterales. Posee crucero no sobresaliente, cabecera plana y coro alto a los pies. Una cúpula semiesférica sobre pechinas cubre el crucero; la capilla mayor, brazos del crucero y nave principal, se cubren mediante bóvedas con lunetos. Las naves laterales, conformadas a modo de capillas, aparecen cubiertas por bóvedas de arista [fig. 2, 3 y 5].

A ambos lados de la capilla mayor existen dos estancias utilizadas como sacristía y capilla del Sacramento. A los pies, y en el lado del Evangelio, se encontraba el antiguo baptisterio. A continuación existen otras tres capillas intercomunicadas, en correspondencia con las del lado de la Epístola. El coro se sitúa a los pies de la iglesia, sobre un amplio arco escarzado. El campanario es una obra de principios del siglo xIX, ya que anteriormente la iglesia poseía una espadaña con varias campanas.

\footnotetext{
${ }^{16}$ Tovar Martín, Virginia, Arquitectura madrileña del S. XVII, Madrid, Instituto de estudios madrileños, 1987, p. 217.
} 
Fuente 3: Iglesia de San Antonio, Mazarrón, Murcia. Planta y proyección de aristas de la cubierta según J. D. de la Hoz y planta propuesta por Fray Lorenzo de San Nicolás en su tratado Arte y uso de la arquitectura.
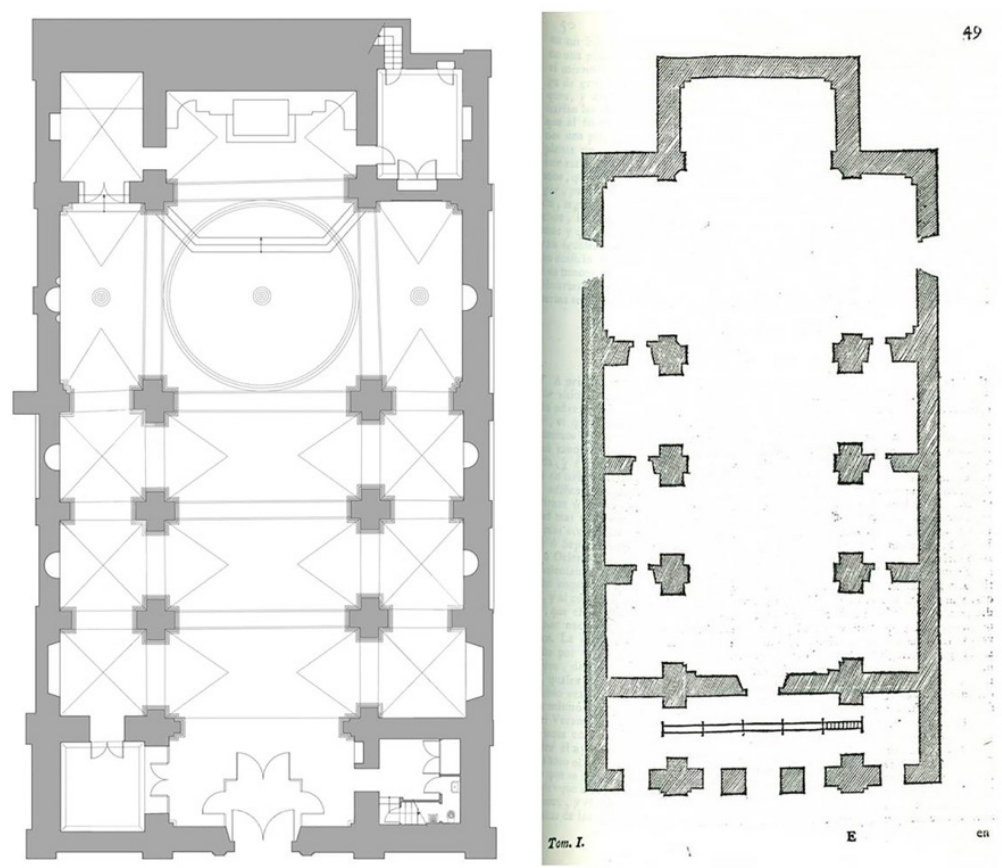

Fuente: J. D. de la Hoz (tomada de su proyecto de restauración) y Fray Lorenzo de San Nicolás, Arte y uso de la arquitectura, Madrid, D.P. Barco López, Tomo I, 1796, lámina 49.

Al exterior, la parte más destacable es la fachada [fig. 1], que se articula verticalmente en tres cuerpos. En el central se halla la portada principal, articulada a su vez en otros dos cuerpos. El inferior, que sirve de entrada al templo, está compuesto por un arco adintelado, y una puerta de dos hojas con herrajes y chapados (siglo XVIII); la cual está enmarcada por dos pilastras cajeadas de orden toscano y fuste rehundido, con rosetas en el equino y ovas en el ábaco, modelo asociado al orden dórico y que se ha querido relacionar con la traza del maestro Juan López Carretero (1647) para un frontis de una capilla en la iglesia de San Agustín de Murcia ${ }^{17}$, aunque como veremos más adelante, esta portada de San Antonio se puede relacionar con obras y artífices posteriores, que trabajan en la ciudad de Lorca.

A continuación, se levanta el segundo cuerpo de esta portada, formado por una edícula, una ventana de reminiscencias paladianas a cada lado de esta y coronada por el ya citado escudo. Un frontón triangular partido, con pináculos piramidales en los laterales y centro, rematados por bolas de ascendencia escurialense, culmina este cuerpo. La edícula central, con nicho avenerado, alberga una imagen pétrea de bulto redondo de San Antonio con el Niño sobre un libro ${ }^{18}$.

\footnotetext{
${ }^{17}$ Agüera Ros, José, "Maestros y trazas de Arquitectura, ingeniería y retablística del siglo XVII en Murcia", en Imafronte, 8-9 (1992), pp. 12-13.

${ }^{18} \mathrm{La}$ escultura se debe a la restauración posterior a la Guerra Civil.
} 
Por cercanía geográfica y estilística, se podría relacionar dicha portada con las trazas que dio el maestro Alonso Pérez Crespo para la portada de la iglesia de San Cristóbal (1651), en la que aparece una hornacina y varias pirámides rematadas por bolas, con las de las iglesias de San Juan (1711), y con la del convento de Nuestra Señora de las Huertas (1690) de Lorca. Estas últimas son, según el profesor Segado, modelos descendientes de la portada de la iglesia de San Cristóbal, que sigue el modelo de hornacina herreriana.

Ante este argumento, no sería aventurado atribuir el diseño de la portada de San Antonio al artífice Manuel Rodríguez Serrano, activo en Lorca a finales del XVII, y posible autor — según Segado - de la portada del convento de Nuestra Señora de las Huertas (1690) ${ }^{19}$; una obra cronológica y estilísticamente cercana a la de San Antonio (1698-1719 Ca.), y que posee un friso tumefacto muy similar al del templo mazarronero.

Por otro lado, por sus semejanzas, resulta inevitable relacionar la iglesia de San Antonio con otros templos erigidos dentro de los antiguos dominios del marquesado de los Vélez, concretamente en la actual provincia de Almería. Ya que, durante el siglo XVIII, el marquesado promovió tanto la erección de nuevos templos como la reforma de los ya existentes en dicha zona.

En un primer período, que corresponde al viII marquesado, con Catalina de Moncada y Aragón (1655-1727) ${ }^{20}$, se construyeron templos como los de la Encarnación de Albanchez (entre 1716 y 1723 Ca.), Nuestra Señora del Rosario de Albox (entre 1718 y $1741 \mathrm{Ca}$.) y la ermita de San Sebastián de Cuevas de Almanzora (entre 1719 y $1728 \mathrm{Ca}$.). Tres construcciones que, como bien señala Torres Fernández, presentan semejanzas entre sí en cuanto a ornamentación; y que nos resultan interesantes por presentar características similares a las que definen la iglesia de Mazarrón, como la presencia de plantas de una o tres naves con crucero poco desarrollado, cubierto por cúpula y cabecera plana; en relación con sus técnicas constructivas; o en cuanto a los órdenes y ornamentos usados ${ }^{21}$.

Durante el período relativo al x marquesado de los Vélez - Antonio María Álvarez de Toledo y Guzmán (1717-1773) — se iniciaron las obras de las iglesias parroquiales de VélezRubio (1754- 1768)22, Cuevas de Almanzora (1754- 1762) y Oria (1767- 1779). En ellas, y de igual modo que ocurre en Mazarrón, se sigue un «estilo más culto y riguroso de la arquitectura, manifestado en la pureza de los órdenes empleados» ${ }^{23}$.

\footnotetext{
${ }^{19}$ Segado Bravo, Pedro, Lorca barroca, Murcia, Editum, 2012, pp. 39-40, 125-128 y 213-256.

${ }^{20}$ Hija de los citados VII marqueses de los Vélez, a quienes debemos parte de la obra de San Antonio.

${ }^{21}$ Para este apartado: Torres Fernández, $\mathrm{M}^{\mathrm{a}}$ del Rosario, "Arquitectura eclesiástica y retablística de los siglos XVII y XVIII", en Ruiz García, Alfonso y Ma Dolores Durán Díaz (coords.), La Almería barroca, Almería, Junta de Andalucía e Instituto de estudios almerienses, 2008, p. 67. Para Albox, véase específicamente: García Campra, Emilio y Antonio Gil Albarracín, La arquitectura de Albox en el siglo XVIII. El obispado almeriense de Claudio Sanz y Torres y el Saliente, Almería, GBG, 1993, pp. 191-264.

${ }_{22}^{22}$ Martínez Nicolás, $\mathrm{M}^{\mathrm{a}}$ del Mar y $\mathrm{M}^{\mathrm{a}}$ del Rosario Torres Fernández, La Iglesia parroquial de la Encarnación de Vélez-Rubio, Almería, Revista Velezana y Ay. de Vélez-Rubio, 1996.

${ }^{23}$ Torres Fernández, Mª del Rosario, “Arquitectura eclesiástica y... op. cit., p. 69.
} 
Asimismo, otros aspectos son testigos de una inequívoca semejanza entre estos templos y la parroquial de San Antonio; destacando el uso de cajas de mampostería con verdugadas de ladrillo, las bóvedas de medio cañón con lunetos y arcos fajones, el uso de cúpulas semiesféricas en los cruceros, así como la presencia de dos torres ${ }^{24}$, o la distribución del espacio bajo un mismo modelo de planta, descendiente de la arquitectura de Fray Lorenzo de San Nicolás, como es el caso de Nuestra Señora de la Asunción de Huércal-Overa (1709-1739) ${ }^{25}$.

Por último, nos gustaría insistir en que las desafortunadas obras realizadas en la iglesia de San Antonio durante los siglos XIX y xx modificaron totalmente la estructura e idiosincrasia original. Especialmente, la última gran restauración del templo — llevada a cabo a finales de los años ochenta del pasado siglo - modificó radicalmente la iglesia a través de la recreación de un barroco historicista, profuso en decoraciones y en llamativas policromías, muy alejado del sobrio estilo de la primitiva fábrica [fig. 2,5 y 6 ].

\subsection{Origen y desarrollo constructivo de la iglesia de San Antonio: siglos XV-XVIII}

\subsubsection{Los orígenes: siglos XV-XVI}

Entre finales del siglo XV y mediados del XVI, el creciente número de nuevos vecinos atraídos por la minería, unido a las obligaciones contraídas por parte de estos marqueses de fundar iglesias y otros servicios, dieron lugar a la erección del templo.

A pesar de la falta de fuentes que documenten su fundación y primeros años, sabemos que en el mismo lugar donde hoy se encuentra la iglesia homónima, se erigió una pequeña ermita consagrada a San Antonio de Padua. La fundación, claro antecedente del actual templo, se debió de realizar al poco tiempo de iniciarse la explotación del alumbre, seguramente bajo influjo de Pedro Fajardo y Chacón, I marqués de los Vélez; Sin embargo, aún teniendo en cuenta estos datos, resulta muy complejo determinar este último aspecto ${ }^{26}$.

Ante estas lagunas, resulta difícil conocer taxativamente la tipología y las características originales del templo, así como sus diferentes fases constructivas. Por el contrario, podemos acercanos a este proceso mediante teorías basadas en la escasa documentación encontrada, en ocasiones inédita.

Así, Alfonso Pérez Sánchez ya afirmó que, entre 1462 y antes de 1549, el marqués de Villena erigió una primitiva ermita consagrada a San Andrés [fig. 4 $]^{27}$. Unas fechas en las que ya encontramos una temprana referencia a un templo fundado por el marquesado de los Vélez

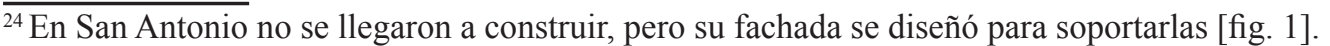

${ }^{25}$ Gomez Ballesta, Pedro, "La Iglesia de Nuestra Señora de la Asunción, Huércal-Overa”, en Ruiz García, Alfonso y Ma Dolores Durán Díaz (coords.), La Almería barroca... op. cit., p. 329.

${ }_{26}^{26}$ Véase nota 36.

${ }^{27}$ Pérez Sánchez, Alfonso, "Iglesias mudéjares del Reino de Murcia”, en Arte Español, 23,3 (1960), p. 106. El primitivo templo, construido a modo de «iglesia de cajón», fue ampliado durante el siglo XVIII, proceso muy similar al que sufrió la iglesia de San Antonio.
} 
en Mazarrón. Se trata de una carta, dada en Escalona el 12 de marzo de 1547, que merece ser citada por ser la primera referencia al templo de San Antonio que conocemos ${ }^{28}$. En la epístola, el III marqués de Villena, Diego López Pacheco, refiere las fundaciones de ambos marqueses en Mazarrón, donde «nunca se a consentido que aya pila ni clérigo puesto por el perlado sino sendos capellanes que tenemos el marqués y yo que dizen misa a la gente a las cuales nosotros pagamos y no consentimos que tengan otro nombre sino de nuestros capellanes» ${ }^{29}$.

Figura 4: Iglesia de San Andrés, Mazarrón, Murcia. Vista exterior y planta con proyección de aristas de la cubierta según J. C. Cartagena Sevilla. En las imágenes se puede discernir claramente la «iglesia-cajón» original con techumbre mudejar; del crucero, presbiterio, capillas anexas y demás espacios añadidos durante la ampliación barroca.
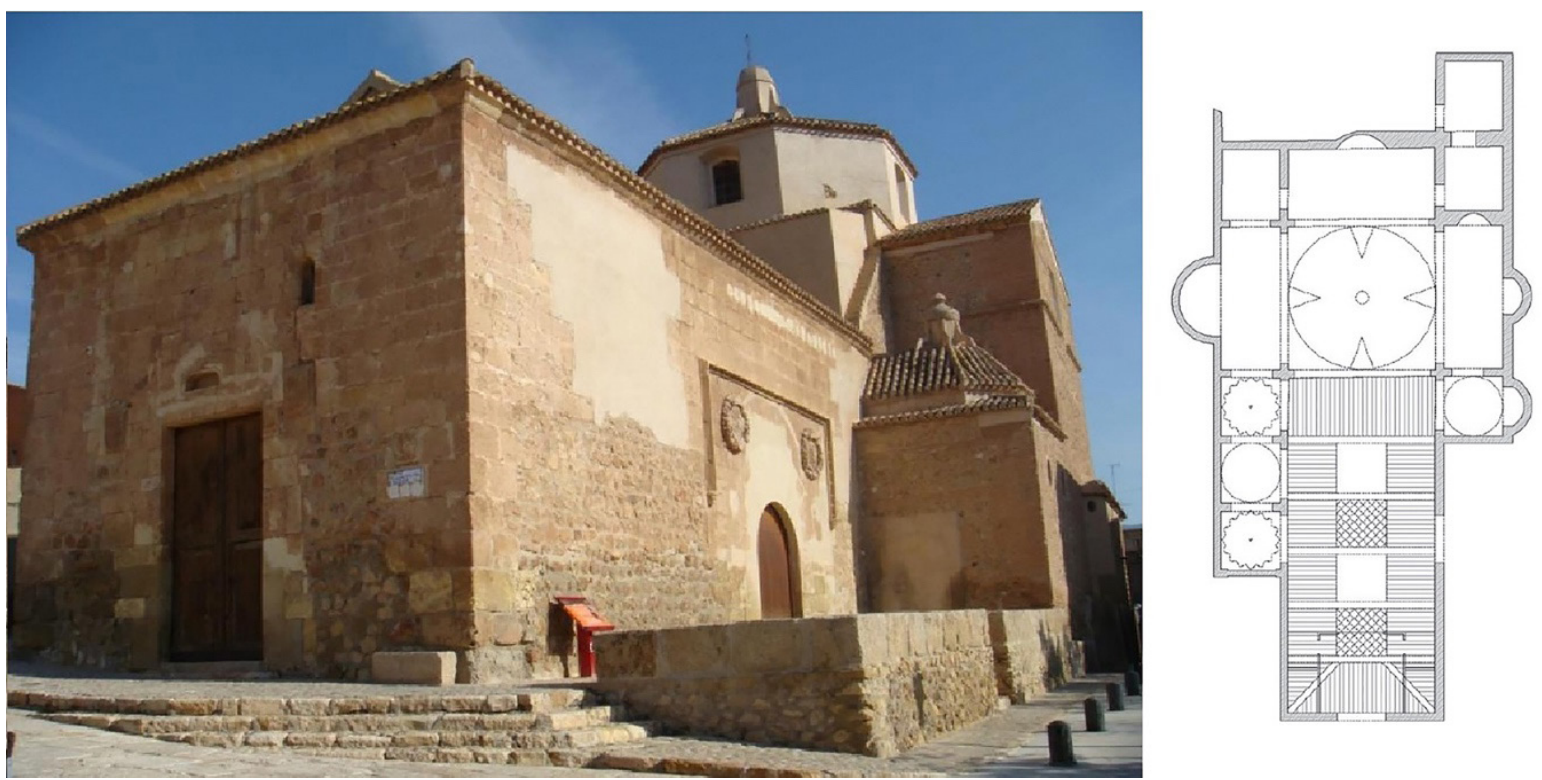

Fuente: J.C. Cartagena Sevilla (tomada de su memoria de restauración).

Teniendo en cuenta que las minas no aparecen organizadas y con disposición de buenos materiales hasta 1485 , momento en el que ya aparece la primera fábrica de alumbre ${ }^{30}$; y que entre los años 1491 y 1494 la hacienda del marquesado hubo de ocuparse de la construcción de la primera fase del Castillo de los Vélez de Mazarrón ${ }^{31}$; parece coherente concretar una horquilla cronológica más exacta, que sitúa la fecha de erección de la primitiva ermita entre inicios del siglo XVI y 1547, fecha de la primera referencia al templo conocida. Además, durante las tres primeras décadas del siglo XVI, las posibilidades económicas del marquesado aumentaron; siendo buena prueba de ello la erección de los castillos de Mula y Vélez-Blanco ${ }^{32}$.

\footnotetext{
${ }^{28}$ Véase, por ejemplo: Jorquera Zamora, Antonio, Cosas y hechos de mi pueblo, Mazarrón, Ay. de Mazarrón, 1998, p. 425.

${ }^{29}$ Transcrita en: Franco Silva, Alfonso, El alumbre... op. cit., p. 326-328.

${ }^{30}$ Franco Silva, Alfonso, El alumbre... op. cit., pp. 17-19.

${ }^{31}$ Empresa de gran envergadura para su hacienda, pero que debió entenderse de primordial necesidad ante la constante amenaza pirata.

${ }^{32}$ López Martínez, Francisco Javier et al., "El castillo de Los Vélez de Mazarrón. Historia, arquitectura y restauración”, en Martínez Alcalde, María y Magdalena Campillo Méndez (Coord.), El Siglo del Milagro. Casas y Villa de los Alumbres de Almazarrón. El exercicio del Hazer Lalum, Murcia, Ayuntamiento de Mazarrón, 2006, p. 62.
} 
La segunda referencia más antigua que se conoce del templo es un inventario de bienes realizado tras la muerte del III marqués de los Vélez, fechado en torno a 1578-79. En él se reflejaba un escaso y pobre patrimonio material, especialmente el litúrgico. Sin embargo, creemos que la primitiva ermita debió de tener unas dimensiones considerables, puesto que poseía «un campanario — presumiblemente espadaña — con tres campanas, un órgano de estaño y su banquillo» y «una caja para enterrar muertos». Estando compuesto su interior de:

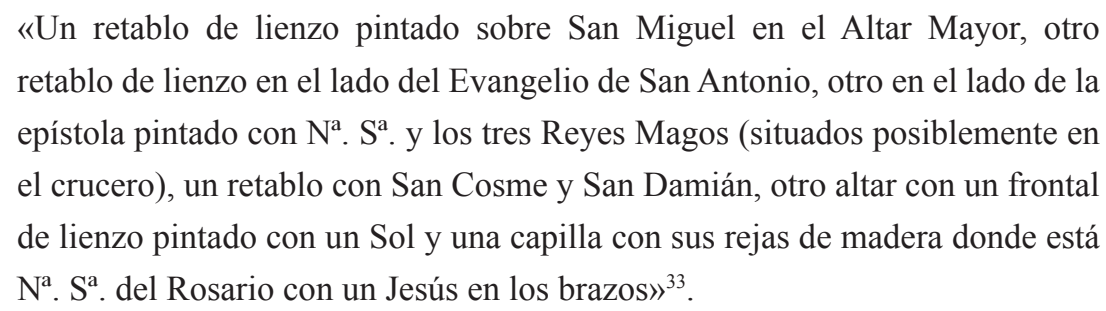

Una descripción que pone de manifiesto la disonancia entre el número de altares de la primitiva ermita y la actual planta de San Antonio [fig. 2 y 3], como resultado de la posterior ampliación que defendemos en este trabajo ${ }^{34}$.

Por otro lado, y aún siendo posteriores, resulta preciso citar aquí dos textos que hablan sobre el origen del templo y su patrocinio: el Memorial del vi marqués de los Vélez solicitando la grandeza de primera clase (1686), donde se afirma que «El I marqués de los Vélez tenía el patrocinio de los conventos de San Ginés de la Jara, San Francisco de Mula y San Diego de Murcia, la excelente capilla de San Lucas de la catedral de Murcia y las iglesias de Mula y Mazarrón ${ }^{35}$ y, sobre todo, la Chronica de la Provincia de San Pedro de Alcántara, de 1761. A través de ella, sabemos que ambos marqueses construyeron ermitas, con el fin de posibilitar el culto religioso a los trabajadores de sus explotaciones mineras:

«Para esta fabrica (...) comenzaron à levantar chozas, que con el tiempo passaron à la formalidad de casas; creciendo tanto su número, que se vieron obligados los dueños à consignarles dos Capellanes, para que tuviessen el consuelo de oir Missa, fabricando algunas hermitas para este efecto ${ }^{36}$.

Tras lo anterior, resulta necesario resaltar que, durante la primera mitad del siglo XVI, una vez construida la ermita, el marqués de los Vélez demostró escasa preocupación por sus haciendas mazarroneras, lo que se tradujo en menor cantidad de alumbre producido, en comparación con el de Villena ${ }^{37}$. Sorprendentemente, en los años de mayores cotas del alumbre

\footnotetext{
${ }^{33}$ Transcrito en: Franco Silva, Alfonso, El alumbre... op. cit., pp. 369-375. Según este inventario, el castillo contaba con dos campanas y un "relox", lo que corroboraría que el castillo sea anterior a la iglesia.

${ }^{34}$ La planta actual comprende un altar mayor, seis capillas laterales y dos estancias a los pies y dos en la cabecera.

${ }^{35}$ Citado en: Hernández Franco, Juan y Raimundo Rodríguez Pérez, "La casa... op. cit., p. 310.

${ }^{36}$ García Alcaráz, Ginés, Segunda parte de las Chronicas de la Santa Provincia de San Pedro de Alcantara, de religiosos menores descalzos de la más estrecha regular observancia de N. S. P. S. Francisco, en los reynos de Granada, y Murcia, Murcia, Nicolás Villargordo, 1761, pp. 178-188.

${ }^{37}$ Que produce más quintales diarios. Franco Silva, Alfonso, El alumbre... op. cit., p. 98.
} 
mazarronero, el marqués no disponía de dinero contante, sufriendo falta de capital entre 1541$1542^{38}$. Así, en una epístola de 1523, entre el señor de Villena y Gonzalo de Mejía, se aludían las fábricas de alumbre del marqués de los Vélez en Mazarrón con un ilustrativo «a de procurar de sostenella», ya que estaban «muy desbaratas y casy desarmadas» ${ }^{39}$. En octubre de 1531, volvían a comentar que «mucho descomedimiento me paresce que tiene (el de los Vélez) en los negocios $\rangle^{40}$.

Por ello, parece lógico atrasar cualquier reforma o ampliación de la primitiva ermita hasta el siguiente siglo; especialmente si se tiene en cuenta la progresiva desaparición de los grandes beneficios del alumbre a finales del siglo $\mathrm{XVI}^{41}$.

\subsubsection{Desarrollo constructivo de la iglesia: siglos XVII-XVIII}

Ante el ambiente de crisis generalizada que dominó el siglo XVII, el alumbre mazarronero jugó un papel menos destacado. Si bien, y como hecho aislado, aún se conserva una campana que «mandó hazer» en 1609 el IV marques de los Vélez, Luis Fajardo, para esta iglesia ${ }^{42}$; la pérdida de la relevancia económica del alumbre dentro de las haciendas del marquesado, mantuvo su desinterés hacia la localidad.

Por ello, tratando de contrarrestar esta problemática, los vecinos desarrollaron una explotación autónoma de almagra; un derivado del alumbre cuyo usufructo podría haber sufragado, a finales del siglo XVII o inicios del XVIII, una ampliación del — seguramente - ya obsoleto templo. Es decir, tras la disminución de las aportaciones económicas del marquesado a esta zona, la mayor parte del dinero para la fábrica de la iglesia procedería ahora de los vecinos del lugar. No obstante, al tratarse de una iglesia de su jurisdicción, y teniendo en cuenta el tradicional patronazgo del linaje en ella, el marquesado se vería forzado, al menos en parte, a contribuir a su fábrica.

Con lo anterior se explicaría la escasa atención que se le prestó al templo en El Libro Becerro de 1635; donde únicamente se detallan las características de su patrocinio, pagándose el «açeyte para la lanpara de la iglesia de San Antón» del que «se gasta de hordinario en ella seis arrovas cada un año» ${ }^{43}$.

Asimismo, fechados en 1614, hemos encontrado varios testamentos en los que se afirma que la iglesia tenía púlpito por aquel tiempo ${ }^{44}$. Algo que, junto a la referencia a la ya citada

\footnotetext{
$\overline{{ }^{38} \text { Ibidem, p. 66-107. }}$.

${ }^{39}$ Ibídem, pp. 34-35.

${ }^{40}$ Ibídem, p. 51.

${ }^{41}$ Ibídem, pp. $55-103$ y $177-180$.

${ }^{42}$ Gremio de Campaners de la Catedral de Valencia, "Inventario de la iglesia de San Antonio". «http:// campanersiglocom/php/catedral.php?numer=2785» [consultado el 3 de mayo de 2016].

${ }^{43}$ Marsilla Pascual, Francisco y Domingo Beltrán Corbalán (coord.), Libro Becerro de la Casa y Estado de Los Vélez. Estudio crítico y transcripción, Murcia, Ayuntamiento de Molina de Segura y Fundación Séneca, 2006, p. 400

${ }^{44}$ Hoy desaparecido.
} 
«Capilla de los Reyes (Magos)», donde Ginés Carvajal tenía enterrada a su mujer ${ }^{45}$, revela la pervivencia del primitivo templo a principios del siglo XVII. Además, estos enterramientos llevados a cabo de manera ininterrumpida durante siglos, prueban que la iglesia nunca fue derruida por completo.

Ante la crisis de los años veinte del siglo XVII, que terminará por dominar toda la centuria ${ }^{46}$, seguiremos retrasando la ampliación del templo. Resultando obvio que, aparte de la coyuntura económica, este retraso también se deba a la presencia del escudo del VII marqués de los Vélez en la fachada de la iglesia, siendo más coherente situar el inicio de las obras de ampliación en torno al citado marquesado, entre 1693 y 1713. Gracias a la nueva documentación que aportamos sabemos que, concretamente, parece que estas obras se realizaron en fechas cercanas a 1698, año del citado enlace entre M. J. Jorquera y D. Alemán Peregrín ${ }^{47}$; y que no debieron exceder de 1719, fecha del contrato para el retablo mayor.

Figura 5: Iglesia de San Antonio, Mazarrón, Murcia, años 80 (antes de la transformación que sufriría unos años después), donde se aprecia la desaparecida decoración geométrica a base de cuadrículas de las bóvedas.

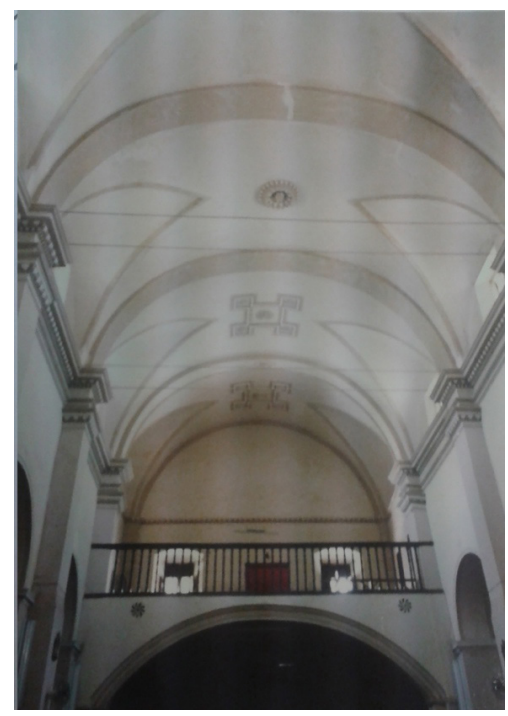

Fuente: Tomada del Catálogo de Bienes Inmuebles (C.A.R.M.), Carpeta 26.00/ 26.014.

En cuanto a su fachada, en esa línea de ambición propagandística iniciada por el vi marqués de los Vélez, sabemos con total seguridad que fue patrocinada —en parte o en su totalidad - por el vir marqués, Fernando de Aragón, y que su construcción conllevó la erección del coro y el cerramiento de las naves en la parte de los pies [fig. 1, 2, 3 y 5] ${ }^{48}$; una obra que pudo rematarse antes de 1713, fecha de la defunción del vir marqués.

${ }^{45}$ AGRM, Notariado, ante Juan de Vivanco, Mazarrón de 1614-21, testamento de G. Carvajal, 1614, prot. 6755, fs.22-23.

${ }^{46}$ Chacón Jiménez, Francisco, Murcia en la centuria del quinientos, Murcia, Universidad de Murcia- Academia Alfonso X el Sabio, 1979, pp. 8-9.

${ }^{47}$ Véase nota 15.

${ }^{48}$ Gracias a las fotografías anteriores a las reformas del siglo xx [fig. 5], sabemos que sobre el coro existía una decoración geométrica a base de cuadrículas - hoy desaparecida-, muy presente durante los siglos XVII y XVIII. Además, la correspondencia existente entre los órdenes del interior y los de la fachada, así como la barandilla del 
Si bien es cierto que el templo fue rehecho casi en su totalidad, algunos elementos y estructuras de la primitiva fábrica pudieron ser reutilizados. Algo que se percibe a través de la irregularidad de sus muros exteriores, la asimetría de algunos elementos, como en el caso de los contrafuertes, o la no correspondencia en las alturas de las techumbres de las naves laterales hacia el exterior ${ }^{49}$.

En el interior del templo, partícipe del denominado «estilo herreriano»o «escurialense» ${ }^{50}$, aparecen capiteles toscanos con una decoración de ovas y dardos; todo ello asociable a la figura del maestro Francisco Bautista [fig. 6], muy presente en la arquitectura murciana de aquel tiempo $^{51}$. Resultando coherente relacionarlos con los capiteles toscanos de las pilastras de la portada, resueltos de igual manera.

Contemporáneamente, se estaban construyendo varias obras relacionadas con la traza de San Antonio, como la portada de la Ermita de Nuestra Señora de las Huertas de Lorca (1690), que también posee un friso tumefacto — presente en San Antonio y en el tratado de Fray Lorenzo de San Nicolás_-, o la iglesia de San Miguel de Murcia (1691-1712), cercana cronológicamente con el vir Marquesado de los Vélez. La torre de la fachada de la iglesia de la Merced (Murcia), iniciada en 1711, también presenta capiteles con ovas y dardos.

Todo ello reafirma nuestra teoría de que la ampliación de la iglesia fue llevada a cabo entre finales del siglo XVII y 1719.

\footnotetext{
coro, parecen corroborar esta idea. Incluso, el cancel que cierra el antiguo baptisterio (siglo XVIII), responde a los motivos y decoraciones presentes en el antiguo retablo mayor y la barandilla del coro de esta iglesia.

${ }^{49}$ Parte de los muros exteriores pueden deberse a la primera fase constructiva, ya que se aprecian irregularidades en algunas verdugadas de ladrillo. Los óculos de estos muros debieron de realizarse tras el proyecto de Jaime Bort para la cúpula del trascoro de la catedral de Murcia (1748 Ca.). En este mismo muro, a los pies del lado de la epístola, se observa un antiguo vano de entrada, cegado en la actualidad.

${ }^{50}$ Estilo de gran fortuna a lo largo del siglo XVII.

${ }^{51}$ García y Bellido, Antonio "La obra arquitectónica del Hermano Bautista" en Tormo, E., El Hermano Francisco Bautista arquitecto, Murcia, Boletín del Museo de Bellas Artes de Murcia, № 7. 1929, sf. Sobre este asunto, y con bibliografía más actual, véase: Marías Franco, Fernando y José Riello Velasco, "La fortuna de Vicenzo Scamozzi en España", en Annali di architettura, 27 (2015), pp. 127- 135. «https://www.palladiomuseum.org/annali/2015/14/ pdf» [consultado el 12 de mayo de 2016].
} 
Fuente 6: Orden dórico que García y Bellido atribuye a Scamozzi (izq.); Iglesia de San Antonio, Mazarrón, Murcia, detalle de uno de los órdenes de las pilastras del interior del (bastante alterado y repintado) (centr.) y —según García y Bellido - Basa, columna y capitel del Hermano Bautista en la catedral de Madrid (der.).
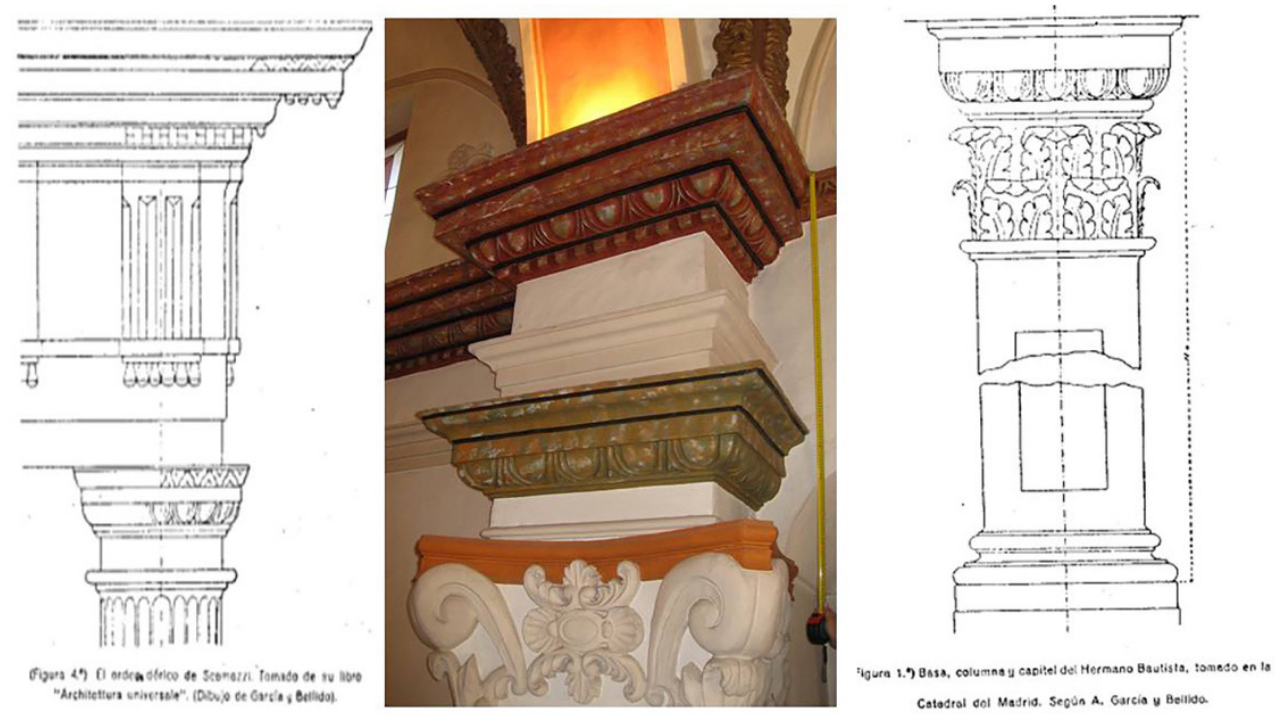

Fuente: G. Bellido, Antonio “La obra arquitectónica... op. cit., Sf.

Por otro lado, hemos hallado un documento inédito donde se reconoce que, en 1707, se estaban llevando a cabo enterramientos en el templo mientras se realizaban importantes obras en el mismo.'Se trata del testamento del médico Baltasar Forner ${ }^{52}$, donde se ordena dejar una cantidad de trigo como limosna para la ejecución de un retablo en la Capilla de la Cofradía de las Benditas Ánimas de dicha iglesia. Limosna que dice tener hecha «con la intención de aplicarlo a un retablo de las Benditas Ánimas, (...) para siempre y cuando sea Dios servido que la iglesia nueva del Señor San Antonio se ponga en perfección», de donde extraemos que el templo aún no había sido rematado en 1707. Con ello, también se prueba la escasa participación del viI marqués de los Vélez en estas obras, al menos a inicios del siglo XVIII. Mientras que, por el contrario, conocemos que el citado marqués estaba construyendo en 1705 el Convento franciscano de Vélez-Rubio, entre otros patrocinios religiosos ${ }^{53}$.

Paralelamente, resulta necesario destacar la relación que esta investigación encuentra entre la traza dada por Melchor de Luzón (1625-1698) en 1695 para la iglesia de la Asunción de Cieza y el templo de San Antonio de Padua, cuya planta no descartamos sea obra de este polifacético artista ${ }^{54}$. Una afirmación que no resulta descabellada si tenemos en cuenta que, por aquel tiempo, a Melchor de Luzón se le encargaron varios proyectos hidráulicos en las

\footnotetext{
${ }^{52}$ AGRM, Notariado, ante Pedro Paredes, Mazarrón 1701-8, testamento de B. Forner, 1707, prot. 6791, f.51.

${ }^{53}$ En 1705 se envían oficiales desde Lorca a Vélez-Rubio para la finalización del remate de la puja del claustro del Convento fundado por el viI marqués de los Vélez (Segado Bravo, Pedro, La Colegiata de San Patricio de Lorca: arquitectura y arte, Murcia, Editum, 2007, p. 71).

${ }_{54}$ Véase: Segado Bravo, Pedro, Melchor de Luzón (ingeniero, escultor, arquitecto, matemático y cosmógrafo), (1625-1698), Calamocha, Ayuntamiento, 1990. Además, entre 1666 y 1675, Melchor de Luzón levantó bóvedas sustentadas sobre arcos fajones en la iglesia parroquial de la Asunción de Almansa, similares a las del templo de San Antonio.
} 
poblaciones de Lorca y Mazarrón ${ }^{55}$. Además, la Asunción de Cieza presenta una distribución semejante a la de San Antonio; ya que su planta también se compone de tres naves divididas en cuatro tramos, cuyos dos últimos corresponderían a estancias, y las demás a capillas laterales, además de un crucero no sobresaliente y testero plano ${ }^{56}$.

Siguiendo con el estudio de la planta de San Antonio, y corroborando nuestras hipótesis respecto a su cronología, hemos encontrado influencias del afamado tratado de Fray Lorenzo de San Nicolás (1593-1679) Arte y uso de la arquitectura (entre 1639 y 1665), cuya propuesta de planta de iglesia se asemeja bastante a la de San Antonio [fig. 2 y 3$]^{57}$.

Por otro lado, las investigaciones de Concepción de la Peña sobre la retablística de San Antonio, nos han servido de base para conocer mejor las fases constructivas del templo. De la Peña fecha el inicio del retablo mayor — destruido en la Guerra Civil - en 1719, que fue construido «para la parroquia de nueva planta de la Villa de Mazarrón» por el maestro Pedro Arandiga y bajo la supervisión de Ginés Granado «cura fabriquero» ${ }^{58}$. Por ello, nos vimos obligados a consultar el contrato de dicho retablo, el cual dice así:

\begin{abstract}
«Por cuanto estaría acabada la fábrica nueva de esta Santa Iglesia parroquial y respecto del mucho gasto que se ha ocasionado con ello, esta Santa Iglesia se halla con mucha necesidad de adornos y especialmente de retablo en su Altar Mayor (...) para mayor culto y veneración posible ${ }^{59} \gg$.
\end{abstract}

El testimonio, nunca antes relacionado con la construcción de la iglesia, corrobora las teorías propuestas en este trabajo en cuanto al desarrollo constructivo de San Antonio y su patronazgo artístico. Además, reconoce el «mucho gasto» y la «necesidad de adornos» que ocasionó la remodelación y ampliación de la iglesia, lo que nos hace pensar que esta hechura debió de ser bastante completa.

Las obras debieron finalizarse en torno a 1719, puesto que era costumbre encargar el retablo mayor inmediatamente después de la finalización del templo. Ante estas evidencias, y como ya habíamos adelantado anteriormente, no cabe pensar que el viI marqués patrocinase por completo las obras de la iglesia de San Antonio de Mazarrón; ya que además, para estas fechas, ya había fallecido.

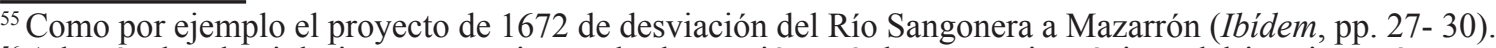

${ }^{56}$ Además, las dos iglesias se asemejan en la decoración y órdenes arquitectónicos del interior, así como en el uso de bóvedas de lunetos abiertas al exterior mediante vanos [fig. 2 y 5]. Aunque menos robusta, la iglesia de la Asunción se resuelve mediante una proporción y serenidad muy similar a la de San Antonio.

${ }^{57}$ Lorenzo de San Nicolás, Fray, Arte y uso de la arquitectura, $4^{\mathrm{a}}$ edición, Madrid, D. P. Barco López, Tomo I, 1796, lámina 49. Este tratado se editó entre 1639 y 1665, y fue uno de los más difundidos en cuanto a arquitectura religiosa durante el siglo XVII. Existen algunas similitudes entre la hechura de San Antonio y el tratado, como por ejemplo la solución del último tramo del templo (coro alto, baptisterio y atrio), el número de capillas laterales (en Mazarrón conforman naves laterales) o el testero plano del presbiterio [fig 2, 3 y 5].

${ }^{58}$ De la Peña Velasco, Concepción, El Retablo barroco en la antigua Diócesis de Cartagena, 1670-1785, Murcia, Colegio de Aparejadores y Arquitectos Técnicos, 1992, pp. 244-245.

${ }^{59}$ AGRM, Notariado, ante Alfonso de Vivanco, Mazarrón de 1718- 21, 1719, prot. 6814, f. 181.
} 
Una escasa participación que resulta asimismo evidente en la necesidad de recurrir a otros medios para obtener fondos para la fábrica del templo. Como testimonio de esto, destacaremos la venta de una capilla de la iglesia, por parte del Cardenal Belluga, al Regidor perpetuo José Zamora y Lardín ${ }^{60}$. Algo que, junto a la donación del Cardenal de 750 r.v. para esta fábrica, prueban nuevamente la parca participación del marquesado en el desembolso total de las obras.

Por último, cabe pensar que se aprovecharan los andamiajes instalados para el remate de la cúpula del crucero o de la hechura del retablo mayor de San Antonio, para colocar los cuatro lienzos octogonales en las pechinas del crucero, unos soberbios lienzos que representan a los Cuatro Santos de Cartagena. Las pinturas fueron atribuidas por el profesor Agüera a un seguidor de los hermanos Gilarte ${ }^{61}$.

\section{Conclusiones}

Mediante esta investigación, hemos tratado de arrojar luz sobre las incógnitas que el templo planteaba, alcanzando una serie de conclusiones que a continuación resumimos:

En primer lugar, hemos concluido que la idiosincrasia y características del actual templo —obviando la reforma del siglo XIX y la malograda restauración de los años 80 — son fruto de una reforma total y ampliación de la iglesia, llevada a cabo entre 1698 y 1719, bajo el influjo del viI marqués de los Vélez; aunque su participación fue más aparente que real, ya que hemos concluido que la población sufragó la mayoría de estas obras.

En segundo lugar, por similitudes con otras edificaciones de su traza, hemos propuesto una intervención del maestro Melchor de Luzón en el diseño de su planta; ya que, en aquellos años, se encontraba trabajando en la zona. Asimismo, por su cercanía geográfica, cronológica y semejanzas estilísticas, hemos propuesto como autor de las trazas de la portada de San Antonio a Manuel Rodríguez Serrano, autor en 1690 de la portada de Nuestra Señora de las Huertas de Lorca.

Por último, hemos concluido que esta gran reforma y ampliación vino motivada a través de la relación que existía entre el marqués y Diego Alemán Peregrín — gobernador general y juez de apelaciones del Estado del vir marqués de los Vélez - que, en 1698, tomó como esposa a la hermana del presbítero de San Antonio, María Josefa Jorquera.

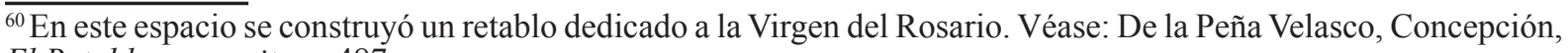
El Retablo... op. cit., p. 487.

${ }^{61}$ Véase: Agüera Ros, José, Pintores y pintura del Barroco en Murcia, Murcia, Tabularium, 2002.
} 